\title{
Primary Central Nervous System Lymphoma High Incidence And Poor Survival In Finnish Population- Based Analysis
}

Inka Puhakka ( $\boldsymbol{D}$ inka.puhakka@kuh.fi )

Kuopio University Hospital

Hanne Kuitunen

Oulu University Hospital

Pekka Jäkälä

University of Eastern Finland Faculty of Medicine

Eila Sonkajärvi

Oulu University Hospital

Taina Turpeenniemi-Hujanen

Oulu University Hospital

Aino Rönkä

Kuopio University Hospital

Tuomas Selander

Kuopio University Hospital

Miika Korhonen

Kuopio University Hospital

Outi Kuittinen

University of Eastern Finland Faculty of Medicine, School of Medicine

\section{Research Article}

Keywords: pcnsl, primary central nervous system lymphoma, incidence, prognosis, survival, cancer registry

Posted Date: December 28th, 2021

DOI: https://doi.org/10.21203/rs.3.rs-1158262/v1

License: (c) (i) This work is licensed under a Creative Commons Attribution 4.0 International License.

Read Full License 
Version of Record: A version of this preprint was published at BMC Cancer on March 3rd, 2022. See the published version at https://doi.org/10.1186/s12885-022-09315-8. 


\section{Abstract}

Background: We report here the first population-based incidence rates and prognosis of primary central nervous system lymphoma (PCNSL) in Finland.

Methods: Finnish Cancer Registry data by histological diagnosis and tumor location (2007-2017) for cases with diffuse large B-cell lymphoma.

Results: During 2007-2017, 392 new cases of PCNSL were reported (195 males, 197 females). The average age-adjusted incidence was $0.68 / 100.000$ person-years. Incidence for males was $0.74 / 100.000$ and for females $0.63 / 100.000$, respectively. The incidence was highest, $2.93 / 100.000$, among people aged 75-79 years. Concerning all cases in 2007-2017 the 2-year age-adjusted relative survival rate was $35 \%$ and the corresponding 5 -year survival rate was $28 \%$. Among patients under the age of 70 , the ageadjusted 5-year relative survival rate increased from $36 \%$ in $2007-2012$ to $43 \%$ for $2013-2017$. Among patients aged $70+$ the corresponding survival rates were poor, $7 \%$ and $9 \%$.

Conclusions: PCNSL incidence in Finland is among the highest reported in the world. The annual increase in incidence was $2.4 \%$. The prognosis is still dismal, especially in elderly patients.

\section{Background}

Primary central nervous system lymphoma (PCNSL) is a rare disease. However, several reports have described a growing incidence rate in Western countries (1-6). The reasons for this increase are mostly unknown. A growing number of patients with immunosuppression may explain some proportion of this, but an increase is evident among immunocompetent people as well. Some environmental or lifestyle factors may explain these changes. It also seems that ethnic and genetic factors play a role, given that in the United States, the risk is different for the African American and Caucasian populations $(1,7)$. The literature examining Northern Europe describes incidence rates in Sweden of $0.26 / 100,000$ in the period 2000-2013 (8), in Norway of 0.18/100,000 during 1999-2003 (2), and in Denmark of 0.16/100,000 for 1983-1994 (3).

The prognosis for PCNSL has been poor. Current standard of care includes high-dose methotrexate containing combination chemotherapy and consolidation therapy with autologous stem-cell transplantation or whole brain irradiation $(9,10)$. Several clinical trials with relatively short follow-up times have reported considerable progress in treatment outcomes among selected clinical trial populations (1115). However, this is in contrast to most of the population-based reports, which have demonstrated only minor improvement in long-term survival (1-6).

Here, we report Finnish Cancer Registry (FCR) (16) data concerning PCNSL incidence, age association, and survival patterns for the years 2007-2017.

\section{Methods}


The data were extracted from Finnish Cancer Registry by histological diagnosis and tumor location. The data were ordered from the registry, and we received the completed calculations of the incidence and survival numbers, which we then analyzed. The research group did not take part in the collection of the data.

\subsection{Finnish Cancer Registry}

The FCR, established in 1952, is a nonprofit organization funded by the Cancer Society of Finland (17) and the Finnish Institute for Health and Welfare (18). FCR receives cancer data from hospitals and other institutions providing treatment for cancer patients, health care professionals, pathology and cytology laboratories and Statistics Finland's cause of death data. Health care workers have a statutory obligation to report new cancer cases to the FCR. All cancer notifications since 2008 have been stored and coded by using ICD-0-3 codes (International Classification of Diseases for Oncology, Third Edition, WHO 2000, 1 st revision 2013). FCR has a high level of coverage, which is shown to be over $95 \%$ for solid tumors (19). FCR data do not include information considering possible underlying immunosuppression, such as HIV.

\subsection{Identification of PCNSL in FCR}

Inclusion criteria for the present study were histological or cytological verification of the diagnosis. Because most of the primary central nervous system lymphomas present with diffuse large B-cell lymphoma histology, we restricted the analyze to this entity. For the present study, PCNSLs were defined as lymphomas located within the central nervous system (CNS; brain, eye, leptomeninges, spinal cord). Lesion limited only to the eye was excluded. ICD codes for topography were C70.0-C72.9 and 9680/3 for morphology. The time period was limited to the years 2007-2017, because during earlier periods, the histological subtyping was unreliable.

\subsection{Statistical Analysis}

The incidence rates were calculated as the number of new cases per 100,000 person-years in each year and age-adjusted as the number of new cases per 100,000 person-years using Finnish population 2015 as a reference. Incidence rates were also reported by age groups and gender. The follow-up period was calculated from the date of the diagnosis to the date of the death or the end of the year 2017. A Poisson regression model was used to study annual incidence trends during 2007-2017 and to compare incidence rates in 2007-2012 for 2013-2017. For rate parameters the $95 \%$ confidence intervals ( $95 \% \mathrm{Cl}$ ) were also reported. Survival analyses were calculated using Kaplan-Meier method for all the data and in different age and gender categories. Age-adjusted relative survival rates were calculated as the observed patient survival (that is, overall survival) corrected for the expected survival of an equivalent group in the general population with respect to age, sex and period. This is to eliminate the effect of general changes in 
population survival over time. In order to obtain most up-to-date picture, denoted period analysis was used for survival calculations $(20,21)$. P-values $<0.05$ were set to indicate statistically significant results.

\section{Results}

\subsection{Incidence}

During 2007-2017, 392 (197 females, 50\%) new PCNSL cases were reported (Figure 1). A total of 7\% of the patients were under 50 years old, $15 \%$ were $50-59,37 \%$ were $60-69,31 \%$ were $70-79$ years, and $10 \%$ were aged $80+$ years, as shown in Figure 2. We discovered an increasing age-adjusted PCNSL incidence, from $0.65 / 100,000$ person-years in 2007-2012 to $0.72 / 100,000$ for 2013-2017. For the period 2007-2017, the annual increase in PCNSL incidence was 2.4\% (95\% Cl: 1.9\%-2.9\%, $p<0.001)$. The incidence was highest, at 2.93/100,000 person-years, among patients aged 75-79. The average age-adjusted incidence according to gender and time period is presented in Table 1.

Table 1. The average age-adjusted incidence / 100,000 person-years according to gender and time period.

\begin{tabular}{|lll|}
\hline Period & $\begin{array}{l}\text { Male, average age-adjusted } \\
\text { incidence } / 100.000 \\
\text { (variation) }\end{array}$ & $\begin{array}{l}\text { Female, average age-adjusted incidence/ } 100.000 \\
\text { (variation) }\end{array}$ \\
\hline $\begin{array}{l}2007- \\
2009\end{array}$ & $0.70(0.65-0.79)$ & $0.53(0.47-0.59)$ \\
\hline $2010-$ & $0.76(0.45-1.19)$ & $0.61(0.58-0.65)$ \\
2012 & $0.65(0.56-0.76)$ & $0.67(0.45-0.79)$ \\
\hline $2013-$ & $0.75(0.51-0.98)$ \\
\hline 2015 & $0.89(0.84-0.94)$ & $0.76-$ \\
\hline 2017 & & \\
\hline
\end{tabular}

Finnish population 2015 is used as a reference. In brackets is the variation of age-adjusted incidence rates between the specific individual years during the specific time period.

\subsection{Survival}

The 2-year age-adjusted relative survival rate in $2007-2017$ was $35 \%$ (95\% $\mathrm{Cl} 30-40 \%)$. The corresponding 5-year survival rate was $28 \%$ (95\% Cl 23-34\%) (Figure 3a).

Older age was clearly related to an adverse disease outcome. In 2007-2012 the age-adjusted 2-year and 5year relative survival rates among patients aged $70+$ years were $18 \%(95 \% \mathrm{Cl} 9-30 \%)$ and $7 \%(95 \% \mathrm{Cl} 1-$ $27 \%$ ). In 2013-2017 the corresponding rates were $23 \%$ (95\% Cl 13-34\%) and 9\% (95\% Cl 2-23\%). 
For younger patients, under the age of 70, the 2-year age-adjusted relative survival rate increased from $42 \%$ (95\% Cl 33-52\%) in 2007-2012 to $46 \%$ (95\% Cl 36-56\%) for 2013-2017. The corresponding 5-year ageadjusted relative survival rates were $36 \%(95 \% \mathrm{Cl} 25-46 \%)$ and $43 \%(95 \% \mathrm{Cl} 32-52 \%)$, respectively. Ageadjusted survival rates are displayed in Figure $3 \mathrm{~b}$.

\section{Discussion}

Here, we report registry-based incidence rates and outcomes of PCNSL patients in Finland between 2007 and 2017. We discovered an increasing age-adjusted incidence, from $0.65 / 100,000$ in 2007-2012 to $0.72 / 100,000$ for $2013-2017$. This is among the highest reported incidence rates in the world $(4-6,8)$. The annual increase in PCNSL incidence was 2.4\% (95\% Cl: 1.9\%-2.9\%, $p<0.001)$. While the prognosis for PCNSL still seems to be poor, during the study period, a trend to minor improvement in 5-year survival rates for patients under the aged of 70 , from $36 \%$ in $2007-2012$ to $43 \%$ for 2013-2017, was discovered. The prognosis still seems to be poor for aged patients.

PCNSL diagnosis is based on histopathological confirmation from either a brain biopsy or positive cerebrospinal fluid or vitrectomy cytology. Systemic lymphomas are excluded by whole body computed tomography scanning, bone-marrow biopsy and testicular ultrasound in males. We excluded intraocular lymphomas. They are usually located intravitreally and there is no specific topography code for intravitreal location in ICD-0-3 classification. Thus, differential diagnosis between intraocular DLBCL and extraocular orbital DLBCL and is not reliable.

There are several registry-based reports describing an increasing incidence of PCNSL in countries with Western lifestyles $(4-6,8)$. In the United States, the Surveillance, Epidemiology, and End Results (SEER) database shows that the PCNSL incidence has increased from $0.1 / 100,000$ in the 1970 s to $0.4 / 100,000$ in 2013 (4). In the most recent years, the increase seems to be flattening. This incidence growth has been greatest among people aged 70+, at a rate of 4.32/100,000 (22). In Sweden, the overall incidence was 0.26/100,000 between 2000 and 2013, with an average annual increase of $4 \%$ (8). In a population-based study from the Netherlands, the PCNSL incidence increased from 0.30/100,000 for the period 1989-1995 to $0.44 / 100,000$ for $2009-2015$. The incidence particularly increased in age groups over 60 years (6). In Korea, the National Cancer Incidence Database shows that the average incidence of PCNSL was 0.17 between 1999 and 2009, with an annual rise of 9\% (5).

The incidence in Finland seems to be among the highest reported in the world, and there seems to be no flattening of the incidence curve. However, it should be noted that in this study we had data from more recent time periods compared to studies mentioned above, which may have caused some of this difference. The etiology behind this increase is unknown. We believe that it is not explained by improved diagnostics, either. MRI scanning has already been a routine research method in Finland during the study period of 2007-2017 for patients suffering from neurological symptoms as well as for elderly patients. Moreover, in PCNSL, the symptoms progress rapidly, leading to patient deterioration, hospitalization, and diagnosis (23). 
To evaluate whether the PCNSL incidence growth rate could potentially be explained by an increasing use of diagnostic imaging, we compared the incidence rates of PCNSL with the incidence rates of glioma in Finland. The incidence of glioma among the entire Finnish population increased from 6.32/100,000 in 2007-2012 to $6.82 / 100,000$ person-years for 2013-2017, according to data received from the FCR. During the study period of $2007-2017$, the median annual increase in glioma was $1.2 \%$ (95\% Cl: $0.3 \%-2.3 \%$ ). The PCNSL incidence growth rate was higher compared to gliomas but not statistically significant.

Immunosuppression increases the risk of PCNSL. From the FCR data, we were not able to get data about potential underlying HIV infection or other immunosuppression. However, we believe that the number of these patients is small, because the incidence of HIV is very low in Finland (24).

This fact is further supported by detailed unpublished data regarding patient comorbidities from the Oulu University Hospital (OYS) district, which shows that among patients diagnosed between 2000 and 2018, only 1 out of 112 PCNSL cases had a congenital immunosuppressive background, and there were no patients with a history of HIV or organ transplantations (unpublished data from Oulu University Hospital registry).

When analyzing the etiology behind these numbers, the difference in incidence rates between Finland and other Nordic countries is interesting. During corresponding time periods, the incidence in Finland was more than double the corresponding numbers of other Nordic countries. The genetic background of the Finnish people differs remarkably from the rest of Europe, and there are also variations in genetics between eastern and western Finns (25).

PCNSL treatment is based on intravenous high-dose methotrexate combined with other immunochemotherapeutic agents $(9,10)$. In Finland a Bonn regimen (26) was mostly used as a standard of care during the study period. Simultaneously high-dose therapy and autologous stem cell transplantation were gradually adopted to routine clinical practice. In Finland radiotherapy has been used only for patients whose poor performance status prevents immunochemotherapeutic treatment or who do not respond to the treatment. Since 2008 over 80 patients have also been treated with blood-brain barrier disruption treatment (BBBD) $(27,28)$ in OYS, 27 patients within a phase two prospective trial and mostly outside the trial.

Worldwide, the prognosis for PCNSL has been dismal, though in isolated ocular disease the prognosis is known to be better $(29,30)$. Nevertheless, in recent years, several studies have reported considerable progress in treatment outcomes (11-15,31). For example, in the International Extranodal Lymphoma Study Group-32 (IELSG-32), the 30-month progression-free survival rate in the group treated with MATRix regimen (methotrexate, cytarabine, thiotepa, and rituximab) was $49 \%$, compared with $23 \%$ of those treated with methotrexate-cytarabine alone and $30 \%$ of those treated with methotrexate-cytarabine plus rituximab (13). This is in sharp contrast to the fact that in most population-based studies, the outcome is still poor, especially among older age groups $(2,5,6,8,22,32)$. In Sweden, there was no sign that new treatment options had translated into general survival improvements in a population-based study covering 2000-2013 (8). In the United States, data from two national databases examining survival 
trends over time showed that the survival rate has increased in younger patients, while the survival rate among the elderly population has not changed in the 40 years from 1970 to $2010(22,32)$. In the United States, the 5-year overall survival rate increased from 19\% in 1992-1994 to 30\% in 2004-2006 (4). Also, in a population-based study from the Netherlands, the 5 -year relative survival rate improved from $22 \%$ in $1989-1995$ to $56 \%$ in $2009-2015$ in patients under age 60 , but at ages over 70 , the corresponding rates were $3 \%$ and $6 \%$, respectively. The overall 5 -year age-adjusted survival rate increased from $11 \%$ in $1989-$ 1995 to 30\% in 2009-2015 (6). In Korea, the overall 5-year survival rate was 30\% between 1999 and 2007. Among patients aged 50 and younger (children included), the rate was $40 \%$, and at ages older than 70 , the corresponding rate was $4 \%$ (5). In general, our results seem to be in line with those from the United States and Korea, where we discovered a trend toward improved survival in later periods. The reason for this improvement is probably the increasing use of combination immunochemotherapy.

In several prospective clinical studies, the treatment results are clearly better compared to populationbased studies $(13,15)$. There may be several factors explaining this discrepancy. One is the fact that many PCNSL patients have poor performance status during diagnosis, which is usually an exclusion criterion in prospective clinical studies. Elderly patients are also rarely included. Because age and performance status are the most important prognostic factors, this means that most prospective trials recruit only the cases with the most favorable prognosis. Another possible reason for the discrepancy is that in contrast to other aggressive lymphomas, PCNSL is a disease that may relapse many years after the diagnosis $(33,34)$. In a Finnish retrospective study, the long-term results for immunochemotherapytreated PCNSL patients showed a constant pattern of relapse. Though demonstrating a favorable 2-year progression-free survival rate of $53 \%$, after longer follow-up period, only 1 patient out of 54 remained in remission at 60 months (33). This was discovered also in a Japanese study with a follow-up for 14 years (35). Because prospective trials are usually reported with limited follow-up time, a considerable number of patients will relapse after follow-up. Getting reliable insight into treatment efficacy a 10-year follow-up, at least, is mandatory. In a population-based setting, new treatment options have not yet translated into major general survival improvements, although the presence of long-term survivors among fit patients is encouraging.

\section{Conclusions}

This study provides the first population-based estimates of PCNSL incidence and survival rates in Finland. A higher PCNSL incidence in comparison to other Nordic and European countries was discovered, which is unlikely to be caused by improved diagnostics. The change in age distribution towards older age may explain part of this. We found minor improvements in PCNSL survival during the study period, probably due to improved treatment options, although the survival of aged patients is still dismal.

We discovered a high incidence rate, but if some systemic error exists, we consider it would more likely be an underestimation than an overestimation. To get reliable data, we focused only on patients with diffuse large B-cell lymphoma, which excludes the few cases with miscellaneous histologies. Only biopsy-proven 
cases were included, and the fact that all aged patients with a declining physical performance status will not proceed to diagnostic biopsy would further underestimate the incidence rate. Cases with eye involvement only were also excluded. There is however a chance that the difference in survival rates between the time periods is due to random variation.

\section{Declarations}

\subsection{Ethics approval and consent to participate}

Our study did not include any experiments on humans or the use of human tissue. The study is retrospective and all the data were extracted with fully anonymized form. For these reasons, according to Finnish laws, no approval from an ethical committee was warranted. Methods were carried out in accordance with relevant guidelines and regulations. Consent to participate not applicable.

\subsection{Consent for publication}

Not applicable.

\subsection{Availability of data and materials}

Finnish Cancer Registry delivered the material. The data that support the findings of this study are available from Finnish Cancer Registry but restrictions apply to the availability of these data, which were used under license for the current study, and so are not publicly available. Data are however available from the authors upon reasonable request and permission of Finnish Cancer Registry.

\subsection{Competing interests}

There are no declarations of interest.

\subsection{Funding}

The data were received from the FCR without any costs. Partial financial support was received from Pohjois-Suomen terveydenhuollon tukisäätiö (TERTTU foundation) (36) for the preparation of the article. It did not have any role in study design, collection or analysis of the data, writing of the report or the decision to submit the article for publication.

\subsection{Authors' contributions}

IP planned and executed conceptualization, methodology and formal analysis and helped to prepare figures and was also a major contributor in writing the manuscript.

HK reviewed and edited the manuscript.

PJ worked with conceptualization and supervision. 
ES reviewed the manuscript.

TT-H reviewed the manuscript.

AR helped with writing, reviewing and editing.

TS helped with formal analysis and prepared the figures.

MK helped with writing, reviewing and editing and also took care of visualization of the manuscript.

OK planned and executed conceptualization, methodology, formal analysis and was also a major contributor in writing and supervision of the manuscript.

All authors read and approved the manuscript.

\subsection{Acknowledgements}

The authors wish to give special thanks to the Finnish Cancer Registry for the data on PCNSL incidence and survival.

Compliance with ethical standards.

\section{References}

(1) Dandachi D, Ostrom QT, Chong I, Serpa JA, Giordano TP, Kruchko C, et al. Primary central nervous system lymphoma in patients with and without HIV infection: a multicenter study and comparison with U.S national data. Cancer Causes Control 2019 May 01;30(5):477-488.

(2) Haldorsen IS, Krossnes BK, Aarseth JH, Scheie D, Johannesen TB, Mella O, et al. Increasing incidence and continued dismal outcome of primary central nervous system lymphoma in Norway 1989-2003 : time trends in a 15-year national survey. Cancer 2007 October 15;110(8):1803-1814.

(3) Krogh-Jensen M, D'Amore F, Jensen MK, Christensen BE, Thorling K, Pedersen M, et al. Clinicopathological features, survival and prognostic factors of primary central nervous system lymphomas: trends in incidence of primary central nervous system lymphomas and primary malignant brain tumors in a well-defined geographical area. Population-based data from the Danish Lymphoma Registry, LYFO, and the Danish Cancer Registry. Leuk Lymphoma 1995 October 01;19(3-4):223-233.

(4) Shiels MS, Pfeiffer RM, Besson C, Clarke CA, Morton LM, Nogueira L, et al. Trends in primary central nervous system lymphoma incidence and survival in the U.S. Br J Haematol 2016 August 01;174(3):417424.

(5) Shin SH, Jung KW, Ha J, Lee SH, Won YJ, Yoo H. Population-based Incidence and Survival for Primary Central Nervous System Lymphoma in Korea, 1999-2009. Cancer Res Treat 2015 October 01;47(4):569574. 
(6) van der Meulen M, Dinmohamed AG, Visser O, Doorduijn JK, Bromberg JEC. Improved survival in primary central nervous system lymphoma up to age 70 only: a population-based study on incidence, primary treatment and survival in the Netherlands, 1989-2015. Leukemia 2017 August 01;31(8):18221825.

(7) Pulido JS, Vierkant RA, Olson JE, Abrey L, Schiff D, O'Neill BP. Racial differences in primary central nervous system lymphoma incidence and survival rates. Neuro Oncol 2009 June 01;11(3):318-322.

(8) Eloranta S, Branvall E, Celsing F, Papworth K, Ljungqvist M, Enblad G, et al. Increasing incidence of primary central nervous system lymphoma but no improvement in survival in Sweden 2000-2013. Eur J Haematol 2018 January 01;100(1):61-68.

(9) Grommes C, Rubenstein JL, DeAngelis LM, Ferreri AJM, Batchelor TT. Comprehensive approach to diagnosis and treatment of newly diagnosed primary CNS lymphoma. Neuro Oncol 2019 February 19;21(3):296-305.

(10) Grommes C, DeAngelis LM. Primary CNS Lymphoma. J Clin Oncol 2017 July 20;35(21):2410-2418.

(11) Deckert M, Engert A, Bruck W, Ferreri AJ, Finke J, Illerhaus G, et al. Modern concepts in the biology, diagnosis, differential diagnosis and treatment of primary central nervous system lymphoma. Leukemia 2011 December 01;25(12):1797-1807.

(12) Martinez-Calle N, Poynton E, Alchawaf A, Kassam S, Horan M, Rafferty M, et al. Outcomes of older patients with primary central nervous system lymphoma treated in routine clinical practice in the UK: methotrexate dose intensity correlates with response and survival. $\mathrm{Br} \mathrm{J}$ Haematol 2020 March 31.

(13) Ferreri AJ, Cwynarski K, Pulczynski E, Ponzoni M, Deckert M, Politi LS, et al. Chemoimmunotherapy with methotrexate, cytarabine, thiotepa, and rituximab (MATRix regimen) in patients with primary CNS lymphoma: results of the first randomisation of the International Extranodal Lymphoma Study Group-32 (IELSG32) phase 2 trial. Lancet Haematol 2016 May 01;3(5):217.

(14) Phillips EH, Fox CP, Cwynarski K. Primary CNS lymphoma. Curr Hematol Malig Rep 2014 September $01 ; 9(3): 243-253$.

(15) Schlegel U, Pels H, Glasmacher A, Kleinschmidt R, Schmidt-Wolf I, Helmstaedter C, et al. Combined systemic and intraventricular chemotherapy in primary CNS lymphoma: a pilot study. J Neurol Neurosurg Psychiatry 2001 July 01;71(1):118-122.

(16) Finnish Cancer Registry. Finnish Cancer Registry. Available at: https://cancerregistry.fi/. Accessed Jul $19,2020$.

(17) Cancer Society of Finland. Cancer Society of Finland. Available at: https://www.cancersociety.fi/. Accessed Jul 19, 2020. 
(18) Finnish Institute for Health and Welfare. Finnish Institute for Health and Welfare. Available at: https://thl.fi/en/web/thlfi-en. Accessed Jul 19, 2020.

(19) Leinonen MK, Rantanen M, Pitkaniemi J, Malila N. Coverage and accuracy of myeloproliferative and myelodysplastic neoplasms in the Finnish Cancer Registry. Acta Oncol 2016 June 01;55(6):782-786.

(20) Brenner $\mathrm{H}$, Hakulinen T. Long-term cancer patient survival achieved by the end of the 20th century: most up-to-date estimates from the nationwide Finnish cancer registry. $\mathrm{Br} \mathrm{J}$ Cancer 2001 August 03;85(3):367-371.

(21) Brenner H, Soderman B, Hakulinen T. Use of period analysis for providing more up-to-date estimates of long-term survival rates: empirical evaluation among 370,000 cancer patients in Finland. Int J Epidemiol 2002 April 01;31(2):456-462.

(22) Mendez JS, Ostrom QT, Gittleman H, Kruchko C, DeAngelis LM, Barnholtz-Sloan JS, et al. The elderly left behind-changes in survival trends of primary central nervous system lymphoma over the past 4 decades. Neuro Oncol 2018 April 09;20(5):687-694.

(23) Velasco R, Mercadal S, Vidal N, Alana M, Barcelo MI, Ibanez-Julia MJ, et al. Diagnostic delay and outcome in immunocompetent patients with primary central nervous system lymphoma in Spain: a multicentric study. J Neurooncol 2020 June 10.

(24) Finnish Institute of Health and Welfare. Statistical database of the National Infectious Diseases Register. Available at: https://sampo.thl.fi/pivot/prod/fi/ttr/shp/fact_shp?row=area-12260\&column=time12059\&filter=reportgroup-12166. Accessed Jul 19, 2020.

(25) Locke AE, Steinberg KM, Chiang CWK, Service SK, Havulinna AS, Stell L, et al. Author Correction: Exome sequencing of Finnish isolates enhances rare-variant association power. Nature 2019 November 01;575(7783):E4-x.

(26) Seidel S, Pels H, Schlomer S, Kowoll A, Fliessbach K, Engert A, et al. Twenty-year follow-up of a pilot/phase II trial on the Bonn protocol for primary CNS lymphoma. Neurology 2020 December 08;95(23):e3138-e3144.

(27) Doolittle ND, Muldoon LL, Culp AY, Neuwelt EA. Delivery of chemotherapeutics across the blood-brain barrier: challenges and advances. Adv Pharmacol 2014;71:203-243.

(28) Kuitunen H, Tokola S, Siniluoto T, Isokangas M, Sonkajarvi E, Alahuhta S, et al. Promising treatment results with blood brain barrier disruption (BBBD) based immunochemotherapy combined with autologous stem cell transplantation (ASCT) in patients with primary central nervous system lymphoma (PCNSL). J Neurooncol 2017 January 01;131(2):293-300.

(29) Ma WL, Hou HA, Hsu YJ, Chen YK, Tang JL, Tsay W, et al. Clinical outcomes of primary intraocular lymphoma patients treated with front-line systemic high-dose methotrexate and intravitreal methotrexate 
injection. Ann Hematol 2016 March 01;95(4):593-601.

(30) Kim MM, Dabaja BS, Medeiros J, Kim S, Allen P, Chevez-Barrios P, et al. Survival Outcomes of Primary Intraocular Lymphoma: A Single-institution Experience. Am J Clin Oncol 2016 April 01;39(2):109-113.

(31) Ponzoni M, Issa S, Batchelor TT, Rubenstein JL. Beyond high-dose methotrexate and brain radiotherapy: novel targets and agents for primary CNS lymphoma. Ann Oncol 2014 February 01;25(2):316-322.

(32) Furst T, Hoffman H, Chin LS. All-cause and tumor-specific mortality trends in elderly primary central nervous system lymphoma (PCNSL) patients: a surveillance, epidemiology, and end results (SEER) analysis. J Neurosurg Sci 2019 October 08.

(33) Harjama L, Kuitunen H, Turpeenniemi-Hujanen T, Haapasaari KM, Leppa S, Mannisto S, et al. Constant pattern of relapse in primary central nervous lymphoma patients treated with high-dose methotrexate combinations. A Finnish retrospective study. Acta Oncol 2015 June 01;54(6):939-943.

(34) Biccler JL, Savage KJ, Brown PDN, Jorgensen J, Larsen TS, Poulsen CB, et al. Risk of death, relapse or progression, and loss of life expectancy at different progression-free survival milestones in primary central nervous system lymphoma. Leuk Lymphoma 2019 October 01;60(10):2516-2523.

(35) Yamanaka R, Morii K, Shinbo Y, Sano M, Homma J, Tsuchiya N, et al. Late relapse of primary central nervous system lymphoma. Leuk Lymphoma 2017 February 01;58(2):475-477.

(36) Pohjois-Suomen terveydenhuollon tukisäätiö. Pohjois-Suomen terveydenhuollon tukisäätiö. Available at: https://terttusaatio.fi. Accessed Nov 5, 2020.

\section{Figures}




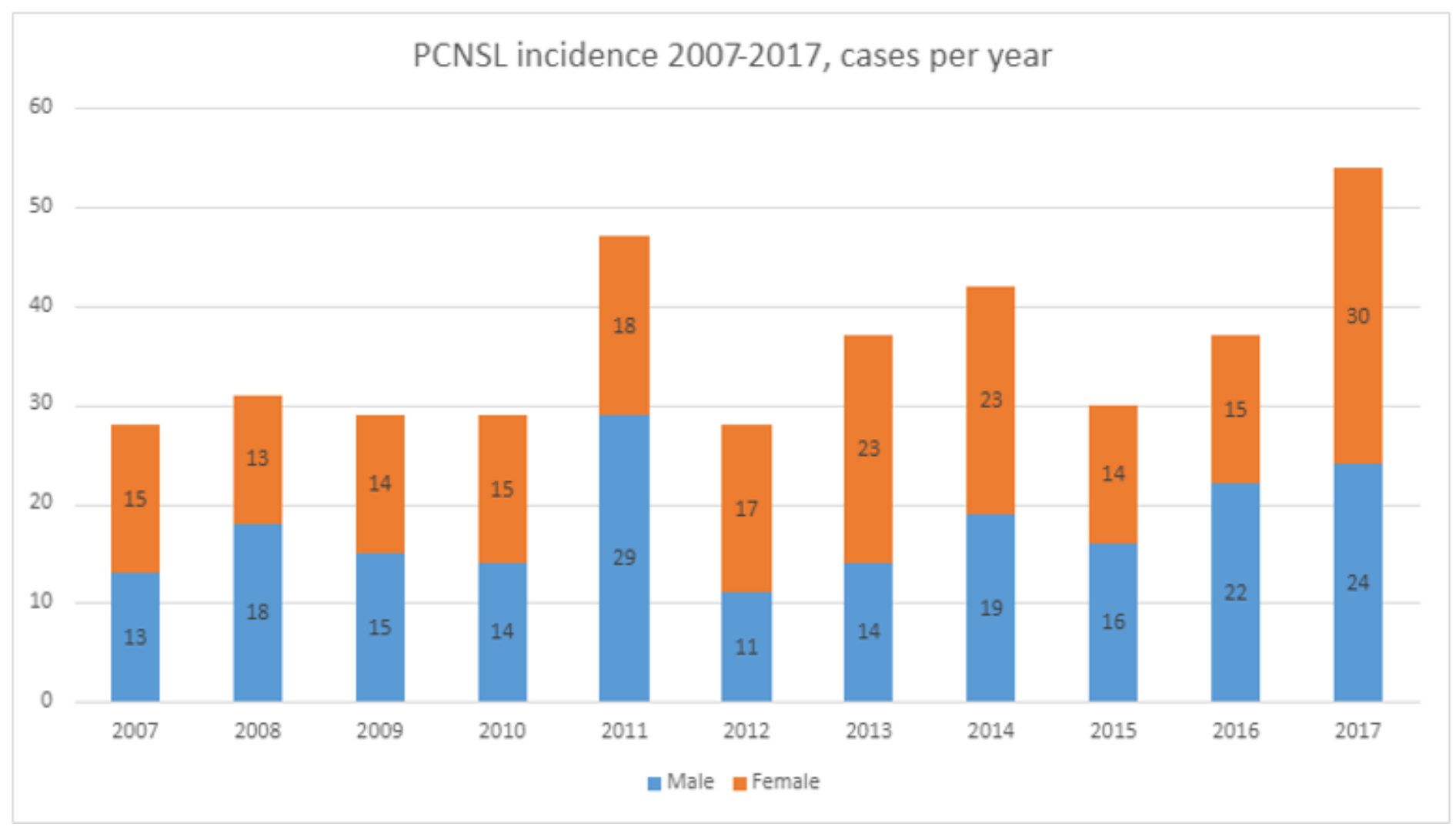

\section{Figure 1}

Primary central nervous system lymphoma (PCNSL) incidence in Finland 2007-2017, cases per year. 


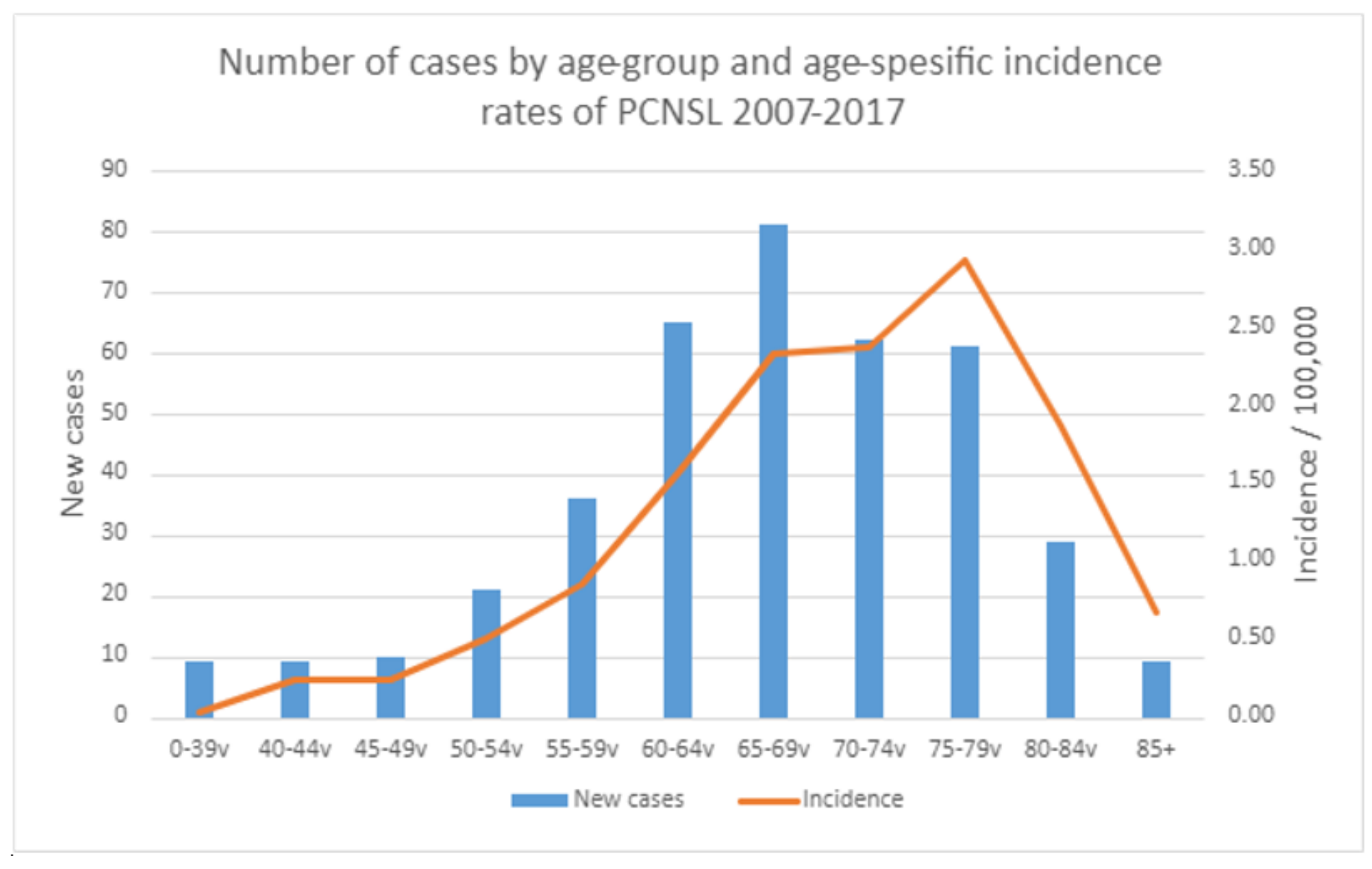

Figure 2

Number of cases by age-group and age-specific incidence rates of PCNSL 2007-2017. 


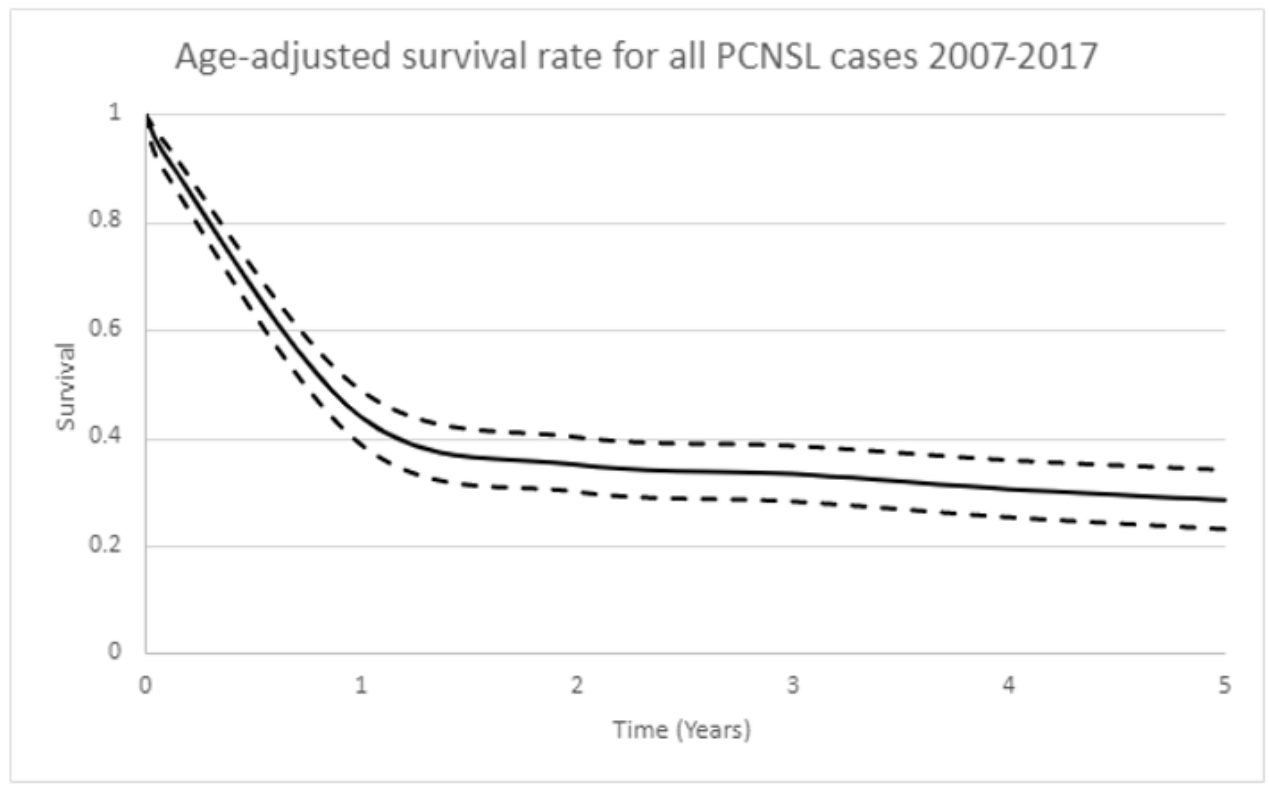

(a)

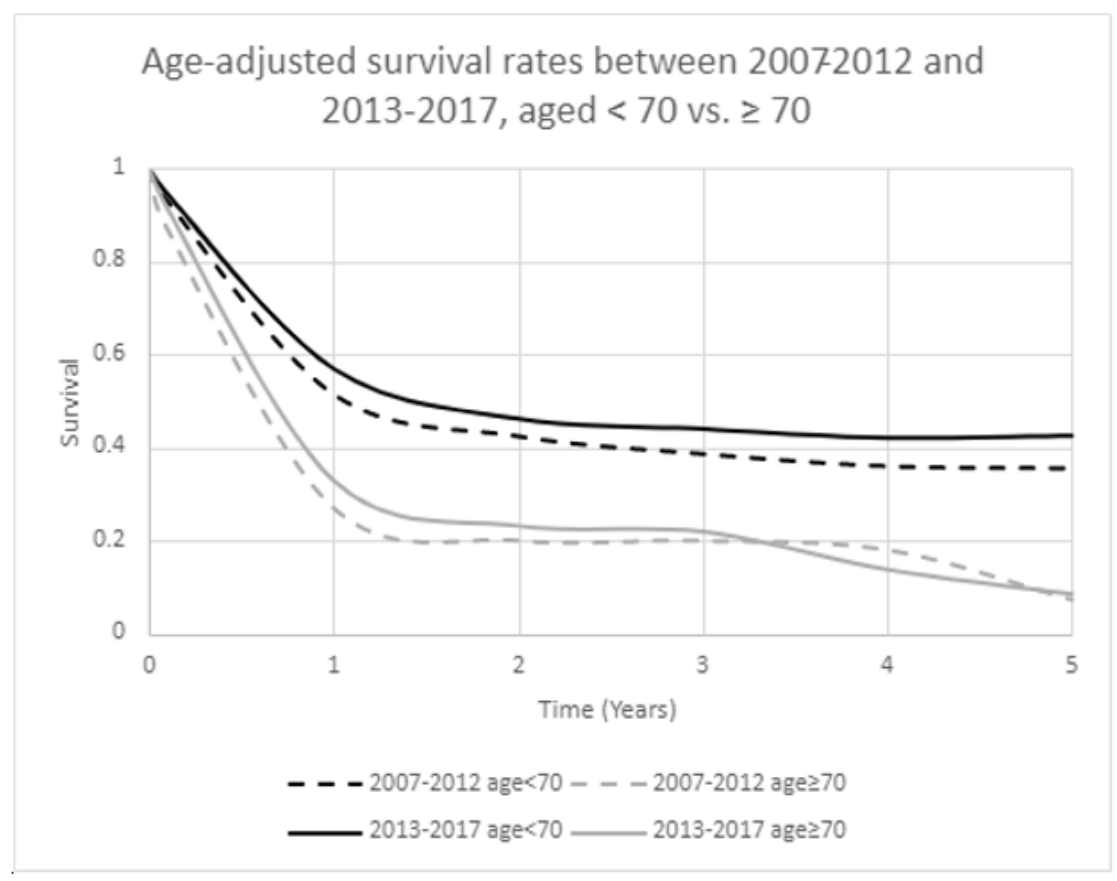

(b)

\section{Figure 3}

a) Age-adjusted survival rate for all PCNSL cases 2007-2017.

b) Age-adjusted survival rates between 2007-2012 and 2013-2017, aged $<70$ or $\geq 70$. 